\title{
Innervation of Two Peptidergic (Substance $P$ and Calcitonin gene-related peptide) Nerves in the Cerebral Arteries and Choroid Plexus of the Japanese Newt (Triturus pyrrhogaster)
}

\author{
Kōichi ANDŌ \\ Department of Regional Culture, Faculty of International Studies of Culture, Kyushu Sangyo University, Matsukadai, Higashi-ku, \\ Fukuoka 813, Japan
}

(Received 25 February 1997/Accepted 2 June 1997)

\begin{abstract}
The pattern of cerebrovascular substance $\mathrm{P}(\mathrm{SP})$ and calcitonin gene-related peptide (CGRP) immunoreactive (-IR) innervation was investigated in the newt. SP-IR nerves supplying the cerebral arterial tree and choroid plexus were positive for CGRP, but negative for vasoactive intestinal polypeptide or neuropeptide Y. It is suggested that cerebrovascular SP- and CGRP-IR axons are sensory in nature. The supply of SP- and CGRP-IR nerves to the major cerebral arteries is relatively poor. Nevertheless, numerous SP- and CGRPIR axons, which are contained in the fiber bundles on the cerebral carotid artery and the basilar artery, spread widely over the microvascular-epithelial regions of the choroid plexuses. It must be considered in relation to the significant role of SP- and CGRP-IR neuronal mechanisms responsible to the microcirculation, cerebrospinal fluid (CSF) production and transport action within the choroid plexus in the nutrition of the newt brain via the CSF.-KEY wORDS: cerebral artery, choroid plexus, newt, SP- and CGRP-IR innervation.
\end{abstract}

J. Vet. Med. Sci. 59(11): 971-976, 1997

The cerebrovascular system of urodelan amphibians is morphologically characteristic when compared with that of other vertebrate groups. Blood vessels in the brain parenchyme are ill-developed in many urodelans including the newt, or almost lacking in some salamanders, despite the systematic supply of pial blood vessels over their brain surface $[17,18,24,25]$. In contrast, the choroid plexus, the special vascular-epithelial structure for the production of cerebrospinal fluid (CSF), is large in relative proportion to the brain and furnished with a well-developed microvascular network throughout the stroma between the epithelial layers $[16,17]$. Moreover, neuronal perikarya in the brain of urodelans are mainly or mostly localized in the periventricular regions facing the CSF [24, 25]. From these morphological profiles, it is considered that the blood supplying to the urodelan brain mainly pours into the choroid plexus, and that the choroid plexus functions as the major site for the supply of nutrients and oxygen to the brain, and for the exit of brain metabolic wastes via the CSF.

Our previous histochemical and immunohistochemical experiments on the newt $[1,2]$ revealed the preferential distribution of noradrenaline/adrenaline (NA/A)-containing, acetylcholinesterase (AChE)-positive and neuropeptide $\mathrm{Y}$ (NPY) immunoreactive (-IR) nerves for the choroid plexuses, especially the microvascular-epithelial regions, than for the major cerebral arteries. This suggests the significance of neurogenic controls for the plexus function. In order to understand more precisely the neuronal influence on the newt's cerebral circulation, the present study was undertaken to investigate the overall distribution of substance $\mathrm{P}$ (SP) and calcitonin gene-related peptide (CGRP)-IR nerves in the cerebral arterial tree and choroid plexus of this urodelan, using double immunostaining for
SP and CGRP, NPY or vasoactive intestinal polypeptide (VIP).

\section{MATERIALS AND METHODS}

Tissue preparation: Twenty five adult Japanese newts (5.7-7.2 $\mathrm{g}$ in weight, $9-11 \mathrm{~cm}$ in total length) (Triturus pyrrhogaster) of either sex were perfused through the heart with Ringer's solution under ethyl ether anesthesia, followed $35 \mathrm{~m} l$ of ice-cold Zamboni's fixative. The brain was removed immediately from the skull, postfixed in Zamboni's fixative for $18 \mathrm{hr}$ at $4^{\circ} \mathrm{C}$. They were then washed with $70 \%$ ethanol, dehydrated in a graded ethanol series, cleaned in xylene, rehydrated in a graded ethanol series, and placed in $0.01 \mathrm{M}$ phosphate buffer (PB, pH. 7.4). For whole-mount preparations, the cerebral arterial tree and choroid plexuses were promptly dissected away from the brain surface and from the lateral, third and fourth ventricles. They were immersed in PB containing $10 \%$ and $20 \%$ sucrose for one day each, and placed in $0.01 \mathrm{M}$ phosphate-buffered saline (pH 7.2) containing $0.3 \%$ Triton X-100 (Wako Chemical, Japan) (PBST). For sectioning, blocks of the brain containing the choroid plexuses were soaked in $\mathrm{PB}$ containing $10 \%$ gelatin for $1-2 \mathrm{hr}$ in vacuo at $38-40^{\circ} \mathrm{C}$ after treatment with sucrose-PB. Gelatin-embedded samples were quickly frozen in acetone chilled with dry ice, sectioned at a thickness of $20 \mu \mathrm{m}$ on a cryostat, and stored at $4^{\circ} \mathrm{C}$ in PBST.

Immunohistochemistry: Whole-mounts and free-floating sections were processed for immunohistochemistry by indirect immunofluorescence as described previously [3]. A series of whole mounts and sections were incubated for 3 days at $4{ }^{\circ} \mathrm{C}$ in rat monoclonal SP antibody, for which the code, working dilution and source is given in Table 1 . They 
Table 1. Details of primary antibodies used

\begin{tabular}{|c|c|c|c|c|c|}
\hline Antigen & Code no & Raised against & Host & Dilution & Source \\
\hline $\mathrm{SP}^{\mathrm{a})}$ & MAB356 & $\begin{array}{l}\text { Synthetic SP-bovine } \\
\text { Serum albumin }\end{array}$ & $\begin{array}{l}\text { Rat } \\
\text { monoclonal }\end{array}$ & $1: 250$ & $\begin{array}{l}\text { Chemicon INC., } \\
\text { California, U.S.A. }\end{array}$ \\
\hline CGRPb) & RPM1842 & $\begin{array}{l}\text { Synthetic CGRP-bovine } \\
\text { Serum albumin }\end{array}$ & $\begin{array}{l}\text { Rabbit } \\
\text { polyclonal }\end{array}$ & $1: 1,000$ & $\begin{array}{l}\text { Amersham, } \\
\text { Buckinghamshire, U.K. }\end{array}$ \\
\hline NPYc) & 09912 & $\begin{array}{l}\text { Synthetic NPY without } \\
\text { conjugation to a car- } \\
\text { rier protein }\end{array}$ & $\begin{array}{l}\text { Rabbit } \\
\text { polyclonal }\end{array}$ & $1: 1,000$ & $\begin{array}{l}\text { Cambridge Res., } \\
\text { Northwich Cheshire, } \\
\text { U.K. }\end{array}$ \\
\hline VIPd) & R7854 & Pure porcine VIP & $\begin{array}{l}\text { Rabbit } \\
\text { polyclonal }\end{array}$ & $1: 1,000$ & $\begin{array}{l}\text { Euro-Diagnostica AB, } \\
\text { Malmö, Sweden }\end{array}$ \\
\hline
\end{tabular}

a) Substance P, b) Calcitonin gene-related peptide, c) Neuropeptide Y, d) Vasoactive intestinal polypeptide.

were washed with PBST, and incubated for $1-2 \mathrm{hr}$ at $37^{\circ} \mathrm{C}$ in rabbit anti-rat $\mathrm{IgG}$ conjugated with fluorescein isothiocyanate (FITC) (Capple, West Chester, PA) at the dilution of 1:200. For double staining, another series of the tissues were first incubated for 3 days in rabbit polyclonal CGRP, NPY or VIP antiserum, and then with sheep antirabbit IgG conjugated with FITC at the dilution of 1:200 (Cappel, West Chester, PA). Next, they were exposed to the rat $\mathrm{SP}$ antibody, and then to rabbit anti-rat $\mathrm{IgG}$ conjugated with Texas Red (TR) (E-Y Laboratories, San Mateo, U.S.A.) at the dilution of 1:500. After being rinsed in $\mathrm{PB}$ and mounted with glycerol-PB, tissues were examined under an Olympus fluorescence microscope. Colocalization of SP and other peptides in the same neurons was achieved by alternation of the filter combination for FITC- and TRinduced fluorescence. The specificity of all the primary antibodies used here was ensured by the control experiments reported previously [2].

\section{RESULTS}

$S P$ - and CGRP-immunoreactive innervation: Nerves with SP or CGRP immunoreactivity were found in the cerebral arterial tree and choroid plexus from all of the 25 newts examined. As a general view obtained from wholemounts of 13 individuals, one or two SP- and CGRP-IR fiber bundles were present on the cerebral carotid artery (CCA), the intracranial part of the internal carotid artery, and the proximal part of the basilar artery (BA) (Figs. 1A and B). SP- and CGRP-IR axons arising from these fiber bundles ran rostrally and caudally to be distributed systematically over the anterior and posterior circulations of the cerebral arterial system, with a striking similarity in density. The IR nerves supplying the newt major cerebral arteries were relatively less (Table 2). A moderate number of SP- and CGRP-IR axons ran longitudinally, spirally or sometimes circularly along the vascular axes of the anterior ramus and tectocerebellar artery, and made up a coarse network on these vessel walls (Fig. 1C). In the vessel walls of BA and posterior ramus, the nerve supply somewhat lowered (Fig. 1B). It became much scarcer in the posterior, middle and anterior cerebral arteries, and in many cases, the
IR axons could not be detectable in the distal parts of these arteries.

The lateral and third choroidal arteries branched from the posterior cerebral artery, and the fourth choroidal artery from the BA received a very poor supply of SP- and CGRP-IR nerves (Fig. 1D). However, a large proportion of SP- and CGRP-IR fiber bundles on the CCA and BA entered the lateral, third and fourth choroid plexuses via the above three arteries, and then spread radially to build up a meshworklike structure of many thin varicose fibers over the plexus proper consisting of the capillary net and epithelial cells (Fig. 1E). In sections prepared from two newts, it was frequently seen that SP- and CGRP-IR axons ran in close association to the microvascular walls and vascular epithelial cells (Fig. 1F). There was no ganglionic structures with SP or CGRP immunoreactivity in any choroid plexuses examined, as well as along the entire length of the cerebral arterial tree.

Double immunostaining: In the four newts labeled doubly with CGRP and SP, CGRP-IR nerves supplying the cerebral arterial tree and choroid plexuses were virtually all immunoreactive for SP and vice versa (Figs. 2A and B). No axons immunoreactive for both SP and NPY were observed in preparations from three animals, although SPIR nerves and NPY-IR ones were distributed in close proximity to each other (Figs. 3A and B). No detectable level of VIP immunoreactivity was found in neuronal elements of the cerebral arterial tree and choroid plexuses from other three animals. When the preparations that reacted negatively to VIP immunohistochemistry were restained with SP antibody, a number of SP-IR axons, which was comparable in density to that demonstrated by single staining, appeared along the cerebral arterial tree and within the choroid plexuses (Figs. 4 and 5A and B).

\section{DISCUSSION}

The present study on the newt is the first description of the cerebrovascular SP- and CGRP-IR innervation in amphibians. In the newt, SP-IR nerves supplying the cerebral arterial tree and choroid plexus are also immunoreactive for CGRP, but have no expression of VIP 

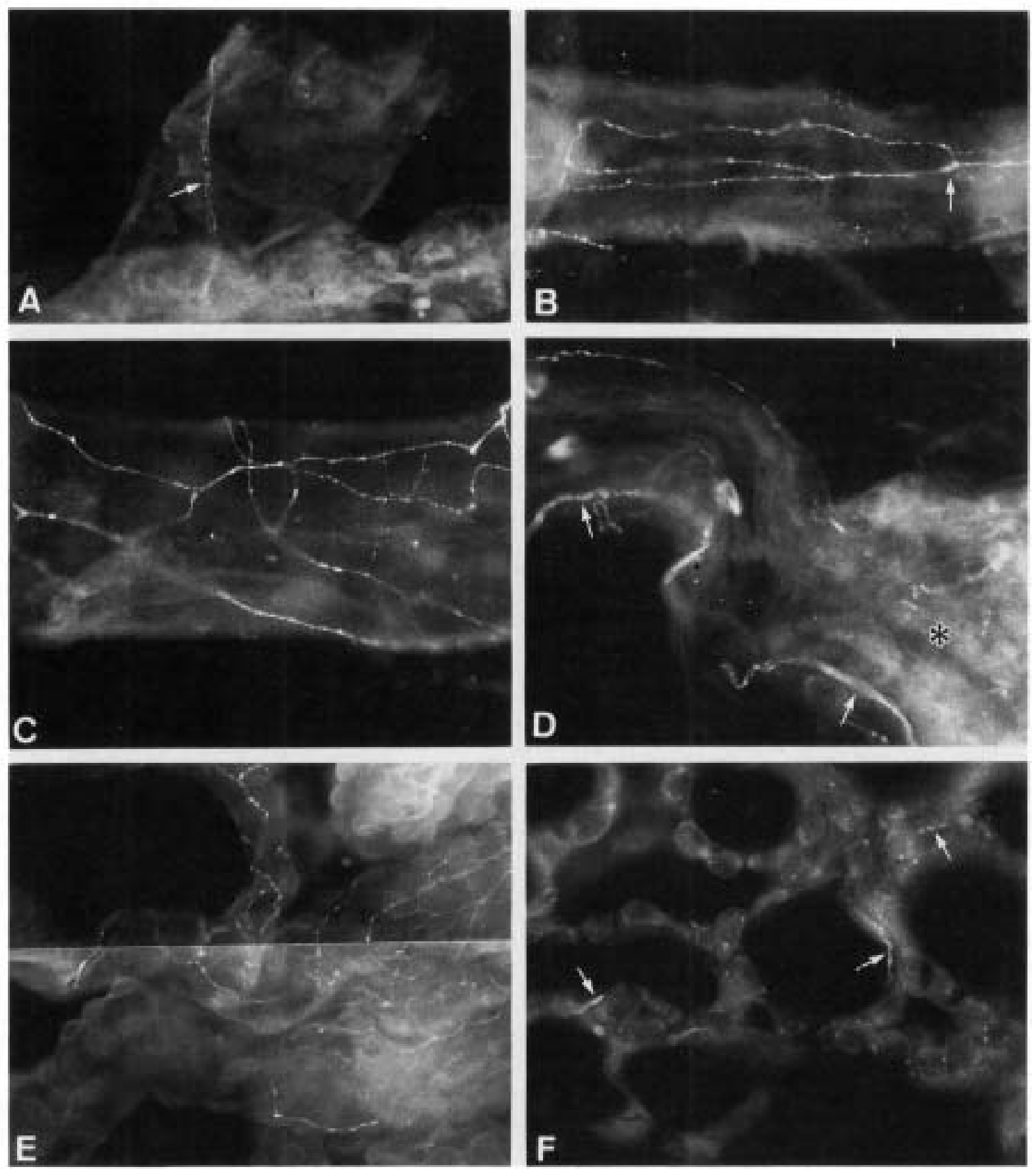

Fig. 1. Fluorescence photomicrographs of whole-mounts (A-E) and section (F) showing SP-IR (A, C, E and F) and CGRP-IR (B and D) innervation of the major cerebral arteries and choroid plexuses. A: cerebral carotid artery. Arrow indicates SP-IR fiber bundle. B: middle part of the basilar artery. Arrow indicates CGRP-IR fiber bundle. C: anterior ramus. D: third and lateral choroidal artery. Arrows indicate CGRP-IR fiber bundles entering into the lateral choroid plexus (asterisk). E and F: Microvascular-epithelial complex of the lateral choroid plexus. Arrows indicate SP-IR axons running in close association to the vascular walls and epithelial cells. A-E: $\times 150, F: \times 300$.

or NPY immunoreactivity. In our preliminary experiment, a population of SP- and CGRP-IR cells negative for VIP or NPY has been ascertained in the trigeminal, cervical dorsal root and vagal jugular ganglia, but no such cells were demonstrated in any other ganglia located in the cranial and cervical regions. Thus, SP- and CGRP-IR nerves in the newt cerebral vasculature, as confirmed in several mammals such as the rat $[15,19]$, guinea pig [28], cat $[8,27]$ and dog 
Table 2. Relative density of SP-IR and CGRP-IR nerves in the major cerebral arteries and choroid plexuses of the newt

\begin{tabular}{|c|c|c|c|c|c|c|c|c|c|c|c|c|}
\hline & \multicolumn{9}{|c|}{ Arteries } & \multicolumn{3}{|c|}{ Choroid plexuses } \\
\hline & \multicolumn{5}{|c|}{$\mathrm{AC}$} & \multicolumn{4}{|c|}{$\mathrm{PC}$} & & & \\
\hline & ACA & MCA & PCA & $\mathrm{AR}$ & $\mathrm{CCA}$ & PR & TCA & $\mathrm{TB}$ & BA & P-L & P-III & P-IV \\
\hline SP & + & + & + & +++ & + & ++ & +++ & ++ & ++ & +++ & +++ & +++ \\
\hline CGRP & + & + & + & +++ & + & ++ & +++ & ++ & ++ & +++ & +++ & +++ \\
\hline
\end{tabular}

+: very few fibers. ++: a few fibers. +++: a moderate number of fibers. AC: anterior circulation. PC: posterior circulation: ACA: anterior cerebral artery. MCA: middle cerebral artery. PCA: posterior cerebral artery. AR: anterior ramus. CCA: cerebral carotid artery. PR: posterior ramus. TCA: tectocerebellar artery. TB: terminal branch of basilar artery. BA: basilar artery. P-L: lateral choroid plexus. P-III: third choroid plexus. P-IV: fourth choroid plexus. SP: Substance P. CGRP: Calcitonin gene-related peptide.

[22], are considered to be sensory in nature. In all probability, this category of cerebrovascular sensory nerves passes through the carotid and vertebral canals to reach the cranial cavity as fiber bundles. The above two neuronal pathways have also been proposed for cerebrovascular sympathetic NA/A-containing and NPY-IR innervation in the newt [1, 2].

SP- and CGRP-IR innervation observed in the newt major cerebral arteries is largely similar in density to NA/Acontaining and NPY-IR innervation [2], and richer than AChE-positive and VIP-IR one [3]. It differs from the general pattern for mammals that is characterized by a lesser density of SP- and CGRP-IR nerves compared to that of the other four nerve types $[4,23,26]$. This is due to the fact that cerebral perivascular NA/A-containing, NPY-IR, AChEpositive and VIP-IR nerves, particularly the latter two nerve types, are definitely less numerous in the newt than in mammals, despite no appreciable difference in the density of SP- and CGRP-IR nerves.

In mammals, only a few SP-IR axons have been reported to be limited to the arterial walls in the guinea pig, rabbit and cat choroid plexuses [11]. In another investigations, however, neither SP nor CGRP immunoreactivities are found in neuronal elements within the plexuses from the same mammals [21]. Thus, it is a subject of controversy whether the mammalian choroid plexus is really innervated by SP- and CGRP-IR nerves. Nevertheless, the present study has demonstrated the wide spread of numerous SPand CGRP-IR axons, which arise from the fiber bundles via the CCA and BA, over the microvascular-epithelial regions of the newt choroid plexus. This finding, although no information on the physiological role of SP- and CGRP-IR nerves has been published for the choroid plexuses in any vertebrates, must be considered in relation to the special requirement for the plexus function of this urodelan.

According to the pharmacological experiments of the effects of SP and CGRP on the cerebral or peripheral blood vessels in the cat and rodents, SP acts as a nonadrenergic and noncholinergic (NANC) vasodilator, and as a mediator of sensory information from blood vessels to the brains [7, 10]. The vasodilatory effect, of SP is dependent on the presence of vascular endothelium [9], caused by endothelium-derived releasing factors such as nitric oxide [14]. CGRP exerts a strong NANC vasodilation that is attributable to the direct action on vascular smooth muscles $[20,27]$. It has also been reported that CGRP potentiates the vascular permeability evoked by SP, and SP regulates CGRP-induced vasodilator activity $[5,6]$. In salivary glands, SP accelerates the exocrine function, especially in protein secretion [13], while CGRP enhances the SP-evoked saliva secretion [12]. In view of such direct and indirect vasomotor, vasosensory, vasopermeable and secretomotor actions of SP and CGRP, the SP- and CGRP-IR innervation focused on the microvascular system and epithelium in the newt choroid plexus seems likely to play an important role for the functioning of these plexus elements in regulating the microcirculation, CSF production and transport exchange between CSF compartment and blood. It may be deeply involved in the neurogenic controlling mechanism responsible for the exchange of oxygen, nutrients and metabolic products between this special vascular-epithelial structure and brain parenchyma via the CSF that has been speculated in urodelan amphibians [24, 25].

ACKNOWLEDGMENT. This work was supported by a grant from the Kyushu Sangyo University.

\section{REFERENCES}

1. Andō, K. 1996. An immunohistochemical study on the innervation of two peptidergic (NPY and VIP) nerves in the cerebral arterial tree and choroid plexus of the newt (Amphibia: Urodela). J. Vet. Med. Sci. 58: 337-342.

2. Andō, K. and Okura, N. 1994. Aminergic and acetylcholinesterase-positive innervation in the cerebral arterial system and choroid plexus of the newt, Triturus pyrrhogaster, with special reference to the plexus innervation. Zool. Sci. 11: 745-752.

3. Andō, K., Ishikawa, A., and Okura, N. 1994. Nature and origin of cerebrovascular nerves with substance $\mathrm{P}$ immunoreactivity in bats (Mammalia: Microchiroptera), with special reference to species differences. J. Comp. Neurol. 347: 357368 .

4. Bevan, J. A. and Owman, C. 1988. Cerebral circulation. pp. 37-62. In: Nonadrenergic Innervation of Blood Vessels, vol 

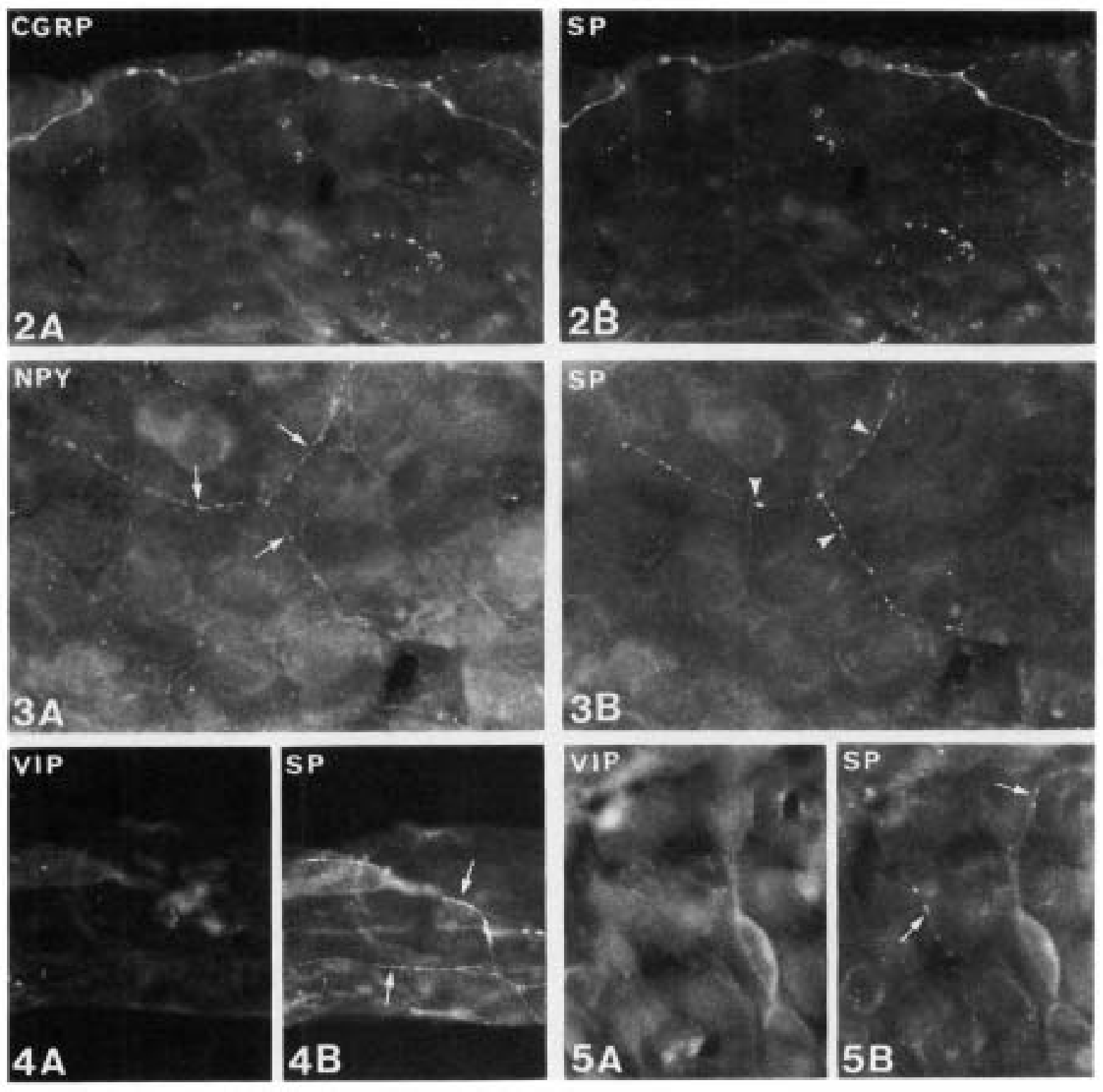

Fig. 2. Fluorescence photomicrographs of whole-mount of the lateral choroid plexus doubly immunostained for CGRP and SP (A and B, respectively). $\times 300$.

Fig. 3. Fluorescence photomicrographs of whole-mount of the third choroid plexus doubly immunostained for NPY and SP (A and B, respectively). Note that NPY-IR axons immunonegative for SP (arrows) and SP-IR axons immunonegative for NPY (arrowheads) run close together. $\times 300$.

Fig. 4. Fluorescence photomicrographs of whole-mounts of the anterior ramus doubly immunostained for VIP and SP (A and B, respectively). Arrows indicate SP-IR axons immunonegative for VIP. $\times 150$.

Fig. 5. Fluorescence photomicrographs of whole-mounts of the fourth choroid plexus. Arrows indicate SP-IR axons immunonegative for VIP. $\times 300$.

II, Regional Innervation (Burnstock, G. and Griffith. S. G. eds.), CRC Press, Florida.

5. Brain, S. D. and Williams, T. J. 1988. Substance P regulates the vasodilator activity of calcitonin gene-related peptide. $\mathrm{Na}$ ture (Lond.) 335: 73-75.

6. Brain, S. D., Williams, T. J., Tippins, J. R., Morris, H. R., and MacIntyre, I. 1985. Calcitonin gene-related peptide is a potent vasodilator. Nature (Lond.) 313: 54-56.
7. Duckles, S. P. and Buck, S. H. 1982. Substance P in the cerebral vasculature: depletion by capsaicin suggests a sensory role. Brain Res. 245: 171-174.

8. Edvinsson, L., Ekman, R., Jansen, I., McCulloch, J., and Uddman, R. 1987. Calcitonin gene-related peptide and cerebral blood vessels: distribution and vasomotor effects. $J$. Cereb. Blood Flow Metab. 7: 720-728.

9. Edvinsson, L., Freedholm, B. B., Hamel, E., Jansen, I., and 
Verrecchia, C. 1985. Perivascular peptides relax cerebral arteries concomitant with stimulation of cyclic adenosin monophosphate accumulation or release of an endotheliumderived relaxing factor in the cat. Neurosci. Lett. 58: 213-217.

10. Edvinsson, L., McCulloch, J., and Uddman, R. 1981. Substance P: immunohistochemical localization and effect upon cat pial arteries in vitro and in situ. J. Physiol (Lond.). 318: 251-258.

11. Edvinsson, L., Rosendal- Helgesen, S., and Uddman, R. 1983. Substance P: localization, concentration and release in cerebral arteries, choroid plexus and dura mater. Cell Tissue Res. 234: 1-7.

12. Ekström, J. 1987. Neuropeptides and secretion. J. Dent. Res. 66: 524-530.

13. Ekström, J., Håkanson, R., Mansson, B., and Tobin, G. 1988. Tachykinin involvement in parasympathetic nerves evoked salivation of the ferret. Br. J. Pharmacol. 94: 707-712.

14. Faraci, F. M. and Brian, J. E. 1994. Nitric oxide and the cerebral circulation. Stroke 25: 692-703.

15. Hanko, J., Hardebo, J. E., Kahrstrom, J., Owman, C., and Sundler, F. 1985. Calcitonin gene-related peptide is present in mammalian cerebrovascular nerves and dilates pial and peripheral arteries. Neurosci. Lett. 57: 91-95.

16. Hinton, W. A. 1953. The choroid plexus of the lateral and third ventricles of tailed amphibia. J. Comp. Neurol. 176: 307-314.

17. Isomura, H. 1959. Studies on the angioarchitecture of the brain in the urodela. Fukuoka Acta Medica 50: 3185-3200.

18. Kubo, T. 1958. Studies on the vascular supply of the newt's brain. Fukuoka Acta Medica 49: 2972-2982.

19. Lee, Y., Kawai, Y., Shiosaka, S., Takami, K., Kiyama, H., Girgis, S., Hillyard, C. J., MacIntre, I., Emson, P. C., and Tohyama, M. 1985. Coexistence of calcitonin gene-related peptide and substance P-like peptide in single cells of the trigeminal ganglion of the rat: immunohistochemical analysis. Brain Res. 330: 194-196.

20. McCulloch, J., Uddman, R., Kingman, T. A., and Edvinsson, L. 1986. Calcitonin gene-related peptide: functional role in cerebrovascular regulation. Proc. Natl. Acad. Sci. U.S.A. 83:
5731-5735.

21. Nilsson, C., Lindvall-Axelsson, M., and Owman, C. 1990. Distribution of peptidergic nerves in the choroid plexus, focusing on coexistence of neuropeptide $\mathrm{Y}$, vasoactive intestinal polypeptide and peptide histidine isoleucine. Regul. Pept. 27: 11-26.

22. Nozaki, K., Uemura, Y., Okamoto, S., Kikuchi, H., and Mizuno, N. 1990. Origins and distribution of cerebro-vascular nerve fibers showing calcitonin gene-related peptide-like immunoreactivity in the major cerebral artery of the dog. $J$. Comp. Neurol. 297: 219-226.

23. Owman, C., Hanko, J., Hardebo, J. E., and Kåhrström, J. 1986. Neuropeptides and classical autonomic transmitters in the cardiovascular system: existence, coexistence, action, interaction. pp. 299-331. In: Neural Regulation of Brain Circulation (Owman, C. and Hardebo, J. E. eds.), Elsevier, Amsterdam.

24. Tsuneki, K. and Ouji, M. 1988. Absence of vessels in the brain of six species of primitive salamanders. Zool. Sci. 5: 847-853.

25. Tsuneki, K., Ouji, M., Akiyoshi, H., and Ichikawa, K. 1986. Absence of blood vessels in the brain parenchyma of hynobiid salamanders. Experientia 41: 1400-1402.

26. Uddman, R. 1987. Peptidergic innervation in cerebro-vascular bed. pp. 15-33. In: Peptidergic Mechanisms in the Cerebral Circulation (Edvinsson, L. and McCulloch, J. eds.), Ellis Horwood, England.

27. Uddman, R., Edvinsson, L., Ekman, R., Kingman, T., and McCulloch, J. 1985. Innervation of feline cerebral vasculature by nerve fibers containing calcitonin gene-related peptide: Trigeminal origin and coexistence with substance P. Neurosci Lett. 62: 131-136.

28. Wanaka, A., Matsuyama, Y., Yoneda, S., Kimura, K., Kameda, T., Girgis, S., MacIntyre, I., Emson, P. C., and Tohyama, M. 1986. Origin and distributions of calcitonin gene-related peptide containing nerves in the walls of the cerebral arteries of the guinea pig with special reference to the coexistence with substance P. Brain Res. 369: 186-192. 